\title{
Cell-adhesive RGD peptide-displaying M13 bacteriophage/PLGA nanofiber matrices for growth of fibroblasts
}

\author{
Yong Cheol Shin ${ }^{1 \dagger}$, Jong Ho Lee ${ }^{1 \dagger}$, Linhua Jin ${ }^{1}$, Min Jeong Kim', Jin-Woo Oh², Tai Wan Kim \\ and Dong-Wook Han ${ }^{1 *}$
}

\begin{abstract}
Background: M13 bacteriophages can be readily fabricated as nanofibers due to non-toxic bacterial virus with a nanofiber-like shape. In the present study, we prepared hybrid nanofiber matrices composed of poly(lactic-coglycolic acid, PLGA) and M13 bacteriophages which were genetically modified to display the RGD peptide on their surface (RGD-M13 phage).

Results: The surface morphology and chemical composition of hybrid nanofiber matrices were characterized by scanning electron microscopy (SEM) and Raman spectroscopy, respectively. Immunofluorescence staining was conducted to investigate the existence of M13 bacteriophages in RGD-M13 phage/PLGA hybrid nanofibers. In addition, the attachment and proliferation of three different types of fibroblasts on RGD-M13 phage/PLGA nanofiber matrices were evaluated to explore how fibroblasts interact with these matrices. SEM images showed that RGD-M13 phage/PLGA hybrid matrices had the non-woven porous structure, quite similar to that of natural extracellular matrices, having an average fiber diameter of about $190 \mathrm{~nm}$. Immunofluorescence images and Raman spectra revealed that RGD-M13 phages were homogeneously distributed in entire matrices. Moreover, the attachment and proliferation of fibroblasts cultured on RGD-M13 phage/PLGA matrices were significantly enhanced due to enriched RGD moieties on hybrid matrices.
\end{abstract}

Conclusions: These results suggest that RGD-M13 phage/PLGA matrices can be efficiently used as biomimetic scaffolds for tissue engineering applications.

Keywords: M13 bacteriophages, RGD peptide, PLGA nanofibers, Extracellular matrices, Fibroblasts

\section{Background}

In the body, most cells grow on the extracellular matrix (ECM) which is porous structure consisting of fibrous proteins and glycosaminoglycans. The ECM is the outer parts of cells in tissues and provides an essential environment for cells to survive. The ECM is very important because it affects cellular behaviors such as cell adhesion, proliferation and differentiation through biochemical or physical signal as well as provides a 3D microenvironment conductive to cellular growth [1-4]. Recently, many efforts are under way to develop a biomimetic artificial ECM for

\footnotetext{
* Correspondence: nanohan@pusan.ac.kr

${ }^{\dagger}$ Equal contributors

'Department of Cogno-Mechatronics Engineering, Pusan National University, Busan 609-735, Korea

Full list of author information is available at the end of the article
}

tissue engineering applications by using various biodegradable polymers [5-7]. Poly(lactic-co-glycolic acid, PLGA), as one of synthetic biodegradable polymers, has been most extensively used in drug delivery and scaffold applications due to its excellent biocompatibility and suitable physicochemical properties [8-11]. Among many biomolecules within the ECM, adhesive proteins such as fibronectin and laminin play an important role in cellular attachment and proliferation. Generally, most of animal cells attach to the ECM through direct interaction between transmembrane integrin receptor and adhesive proteins. The primary sequence motif of fibronectin for integrin binding is a tripeptide, Arg-Gly-Asp (RGD [12-14]. Therefore, matrices which are enriched with RGD peptides promote not only cellular attachment but also cellular behaviors $[15,16]$. 
An electrospinning technique has been widely used to fabricate nanofibrous matrices which were structurally similar to the natural ECM. A previous study has already shown that nanofibrous matrices fabricated by an electrospinning process were suitable for tissue engineering scaffolds [17]. The advantage of this technique is that non-woven porous matrices can be easily produced as well as incorporated with bioactive agents including growth factors, peptides and drugs [7].

M13 bacteriophage is bacterial virus with nanofiberlike shaped [18,19]. Moreover, M13 bacteriophages do not have any detrimental effect on mammalian cells [20-22]. Some previous studies showed that M13 bacteriophage could express many desired proteins on their surface [23-25]. In addition, M13 bacteriophages can be readily fabricated as nanofibers via an electrospinning process due to their structural property [26].

The aim of the present study was to fabricate RGD peptide-displaying M13 bacteriophages (RGD-M13 phages)/ PLGA hybrid nanofiber matrices to mimic the natural ECM by electrospinning. We showed that RGD-M13 phage/ PLGA hybrid matrices were successfully fabricated and RGD-M13 phages were uniformly distributed over the matrices. Furthermore, we examined cellular behaviors of fibroblasts on RGD-M13 phage/PLGA nanofiber matrices to explore how the cells interact with these matrices. As a result, we demonstrated that these matrices improved cellular behaviors by synergistic effects, resulting from the excellent biocompatibility of PLGA and the ability to enhance the cell attachment of RGD sequences displayed on the surface of M13 bacteriophages. Therefore, this result implies that RGD-M13 phage/PLGA hybrid matrices can be one of the best potential candidates for biomimetic tissue engineering scaffolds.

\section{Methods \\ Fabrication of RGD-M13 phage/PLGA nanofibers by electrospinning}

Genetic engineering of M13 bacteriophage was conducted according to the method as previously described [20]. In brief, to display a desired peptide on major coat protein of M13 bacteriophage surface, an inverse PCR cloning method was carried out as described elsewhere [24,27,28]. As shown in Figure $1 \mathrm{~A}-\mathrm{C}$, we built RGD-M13 phages through genetic modification of wild-type M13 bacteriophages. PLGA resins (PLA/PGA $=75 / 25$, MW $=70-$ $110 \mathrm{kDa}$ ) were purchased from Sigma-Aldrich (St Louis, MO). RGD-M13 phage/PLGA nanofiber matrices were fabricated by an electrospinning process (Figure 1D) as described elsewhere [29]. Random oriented RGD-M13 phage/PLGA nanofibers were collected on a steel rotating wheel covered with an aluminum foil. Then, electrospun nanofiber matrices were dried overnight under vacuum at room temperature in order to remove any residual solvent.

\section{Characterizations of RGD-M13 phage/PLGA hybrid nanofibers}

The surface morphology of RGD-M13 phage/PLGA matrices was observed under a scanning electron microscope (SEM). The matrices were coated with an ultrathin layer of gold/platinum by an ion sputter (E1010, Hitach, Tokyo, Japan) prior to analysis. The RGD-M13 phages and nanofibers were characterized by using Raman spectroscopy. For immunofluorescence staining to examine whether M13 bacteriophages exist in RGD-M13 phage/PLGA matrices or not, the matrices were incubated with primary anti-M13 bacteriophage antibody [at 1:250 in 2\% bovine serum albumin (BSA) solution in phosphate-buffered saline (PBS, pH 7.4); Sigma-Aldrich] for $2 \mathrm{~h}$ at room temperature and then incubated with secondary FITCconjugated goat anti-rabbit IgG (at 1:500 in 2\% BSA solution in PBS; Abcam Inc., Cambridge, MA) for $1 \mathrm{~h}$ at room temperature. Immunostained matrices were imaged with an Olympus IX81 inverted fluorescence microscope (Olympus Optical Co., Osaka, Japan).

\section{Cells and culture conditions}

In the present study, three different types of fibroblasts were employed - two types were immortalized and cancerous cell lines and one was a primary cell. Murine fibroblasts (L-929 cells) and human fibrosarcoma cells (HT-1080 cells) were purchased from American Type Culture Collection (ATCC, Rockville, MD) and routinely maintained in Dulbecco's modified Eagle's Medium (DMEM, Welgene, Daegu, Korea). Human dermal fibroblasts (HDFs) from neonatal dermis were kindly provided by Dr. Dong Kyun Rah (Department of Plastic and Reconstructive Surgery, Yonsei University College of Medicine, Seoul, Korea) and cultured in fibroblast basal medium (FBM, Lonza, Basel, Switzerland). All cells were cultured in complete media supplemented with 10\% fetal bovine serum (FBS, Welgene) and 1\% antibioticantimycotic solution (including 10,000 units penicillin, $10 \mathrm{mg}$ streptomycin and $25 \mu \mathrm{g}$ amphotericin B per $\mathrm{ml}$, Sigma-Aldrich, St. Louis, $\mathrm{MO}$ ) at $37^{\circ} \mathrm{C}$ in a humidified atmosphere containing $5 \% \mathrm{CO}_{2}$.

\section{In vitro assays for fibroblast behaviors on RGD-M13 phage/PLGA nanofibers}

Cell attachment and proliferation were measured by using a cell counting kit-8 (CCK-8, Dojindo, Kumamoto, Japan), which contains highly water-soluble tetrazolium salt [WST-8, 2-(2-methoxy-4-nitrophenyl)-3-(4-nitrophenyl)-5(2,4-disulfophenyl)- $2 H$-tetrazolium, monosodium salt], reduced to a water-soluble formazan dye by dehydrogenases in cells. The number of viable cells was found to be directly 


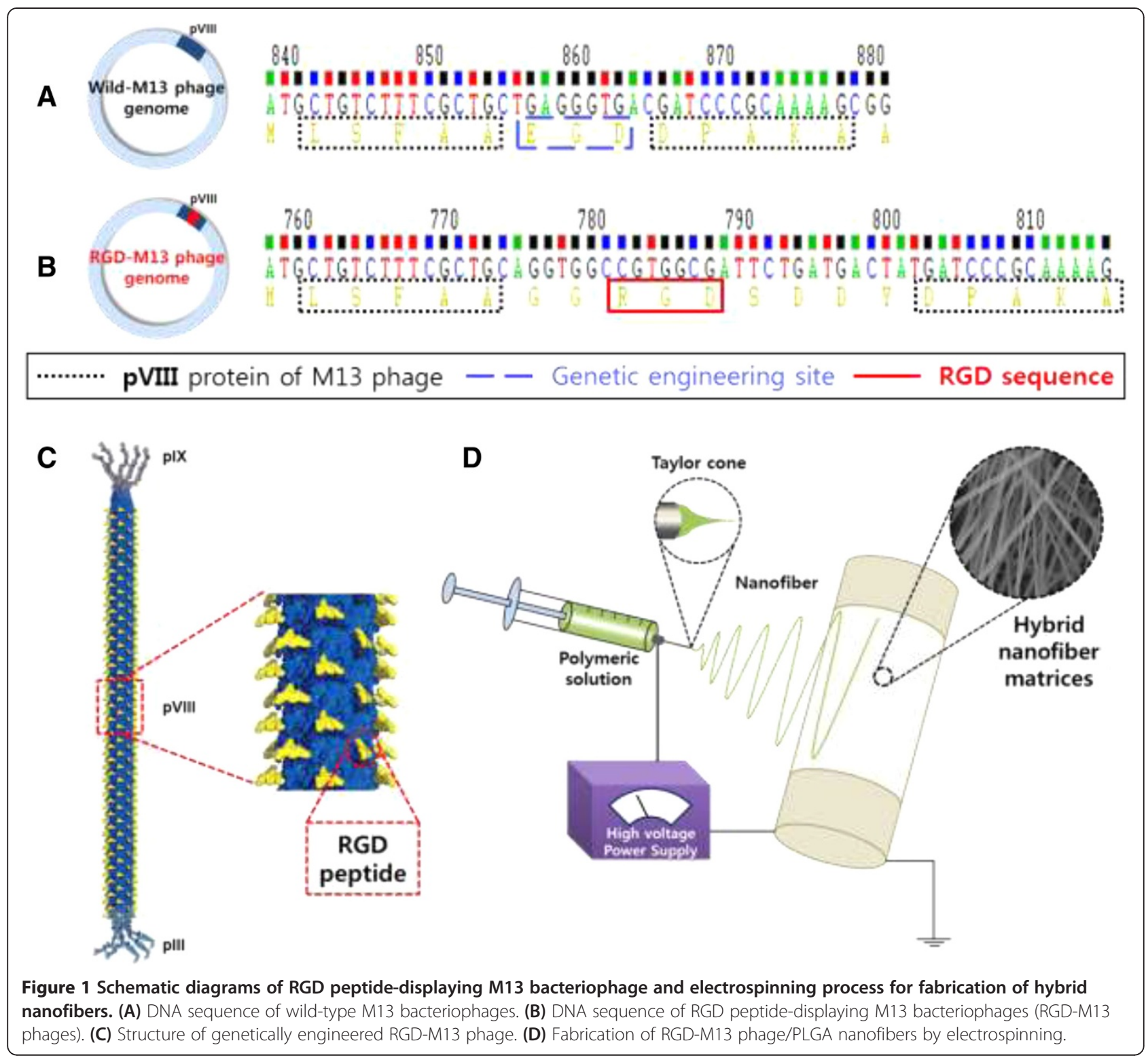

proportional to the metabolic reaction products obtained in the CCK-8 assay [30]. Typically, three types of fibroblasts were seeded at a density of $1 \times 10^{4}$ cells $/ \mathrm{mL}$ on PLGA or RGD-M13 phage/PLGA matrices. According to the manufacturer's instruction, each cell culture was incubated with a WST- 8 solution in the last 4 hours of culture periods for cell attachment ( 6 hours) or proliferation (1, 3, 5 and 7 days) at $37^{\circ} \mathrm{C}$ in the dark. Parallel sets of cells cultured on tissue culture plastics (TCP) were regarded as controls. The absorbance was determined at $450 \mathrm{~nm}$ by an ELISA reader (SpectraMax 340, Molecular Device Co., Sunnyvale, CA). For morphological observations, HDFs cultured on matrices for 3 days were fixed with $3.7 \%$ formaldehyde solution (Sigma-Aldrich) for
10 minutes. After fixation, HDF-cultured matrices were dehydrated in a graded series of ethanol, followed by airdrying overnight. The matrices were sputter-coated with gold/platinum and then observed under a scanning electron microscope (SEM, Hitachi S-800, Tokyo, Japan) at an accelerating voltage of $5 \mathrm{kV}$.

\section{Statistical analysis}

All variables were tested in three independent cultures for each experiment, which was repeated twice $(n=6)$. Quantitative data are expressed as the mean \pm standard deviation (SD). Data were tested for homogeneity of variances using the test of Levene, prior to statistical analysis. Multiple comparisons to detect the cellular behaviors on 
RGD-M13 phage/PLGA nanofiber matrices were carried out using one-way analysis of variance (ANOVA, SAS Institute, Cary, NC), which was followed by the Bonferroni test when variances were homogeneous and the Tamhane test when variances were not. A value of $p<0.05$ was considered statistically significant.

\section{Results and discussion}

Physicochemical characteristics of RGD-M13 phage/PLGA hybrid nanofibers

As shown in Figure 1, RGD-M13 phages and PLGA were blended and then fabricated into hybrid nanofibers thru an electrospinning technique. The artificial scaffolds should be similar to structural property of the natural ECM and support cell growth through 3D microenvironment. As shown in Figure 2A, the morphology of RGDM13 phage/PLGA nanofibers was not only non-woven porous but also uniform and bead-less as similar to the natural ECM. The RGD-M13 phage/PLGA nanofibers had an average diameter of $190 \pm 30 \mathrm{~nm}$ (Figure 2B). The RGD-M13 phages of electrospun nanofibers could be very well interaction with cells because the matrices consisted of nanometer scale fibers had a very high surface area-to-volume ratio. Immunostaining fluorescence image showed that genetically engineered RGD-M13 phages were located on the hybrid nanofibers (Figure 2C). Green fluorescence from RGD-M13 phages labeled with FITC was detected along the RGD-M13 phage/PLGA nanofibers. On the contrary, any fluorescence was not exhibited from pure PLGA nanofibers (Figure 2D).

Raman spectroscopy was used to evaluate the composition of the nanofibers. The Raman spectra of RGD-M13 phages, RGD-M13 phage/PLGA nanofibers and pure PLGA nanofibers were shown in Figure 3. There are many bands representing the PLGA. The strong bands observed at 850 and $1460 \mathrm{~cm}^{-1}$ were assigned to $\mathrm{CH}_{2}$ [31]. Another band observed at $1780 \mathrm{~cm}^{-1}$ represents the $\mathrm{C}=\mathrm{O}$ stretch of the ester group [32]. The spectra of PLGA were more predominant than that of RGD-M13 phages because the ratio of PLGA was much greater than that of RGD-M13 phages in nanofibers. However, there is a specific peak at $1620 \mathrm{~cm}^{-1}$ which can be attributed to bending vibration of $\mathrm{NH}_{3}{ }^{+}$[33]. This peak was derived from amino acids of the RGD-M13 phages. In addition, a characteristic peak was found near $930 \mathrm{~cm}^{-1}$ which is assigned to the $\mathrm{C}^{-\mathrm{COO}^{-}}$stretch from carboxylate group of glycine [31]. These results imply that RGD-M13 phages were existed in the nanofibers. From immunofluorescence staining and Raman spectroscopy, it was demonstrated that RGD-M13 phages were well incorporated into electrospun nanofibers.
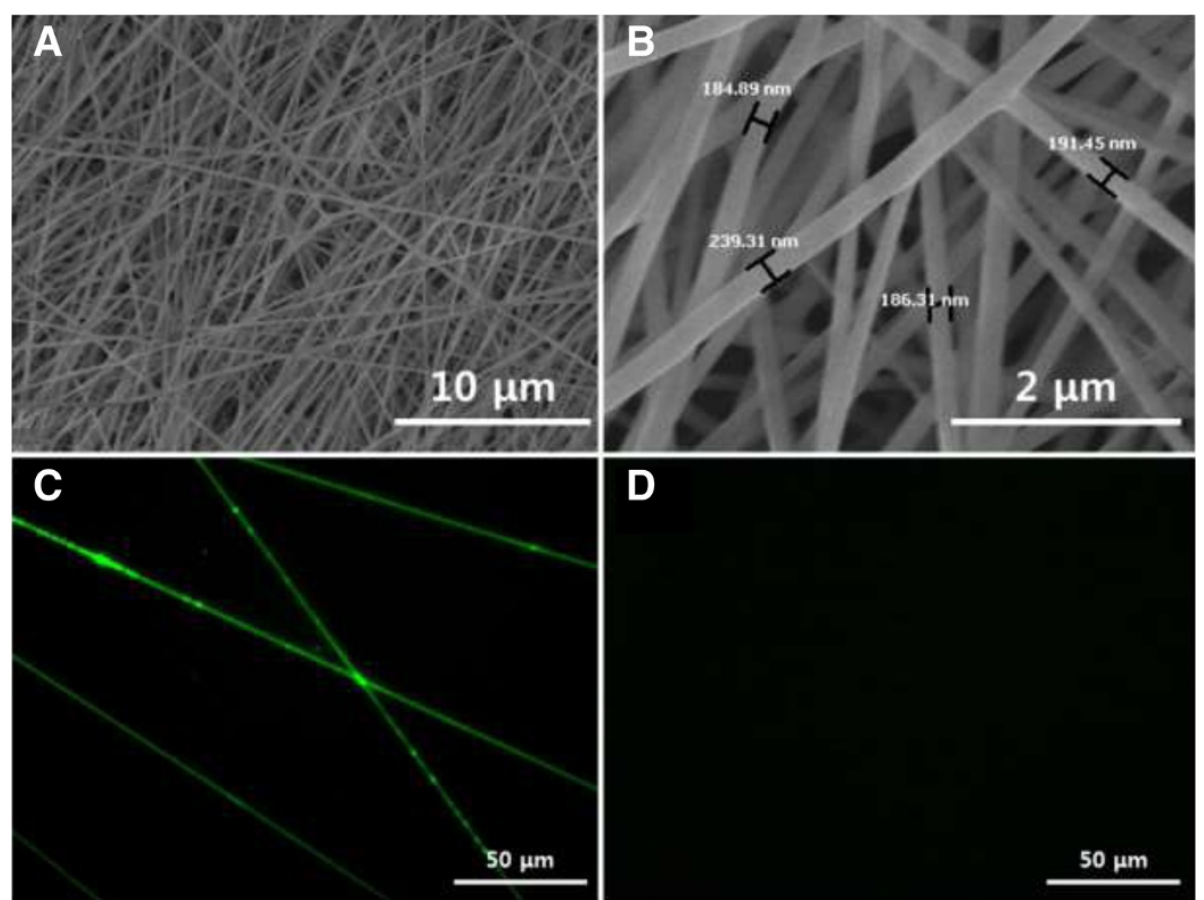

Figure 2 Surface morphology and immunostaining of electrospun nanofibers. (A, B) SEM images of RGD-M13 phage/PLGA nanofibers. Fluorescence microscopic images of RGD-M13 phage/PLGA nanofibers (C) and pure PLGA nanofibers (D). RGD-M13 phages in RGD-M13 phage/ PLGA nanofibers were immunostained with FITC-labeled anti-M13 phage antibody and fluoresced green. 


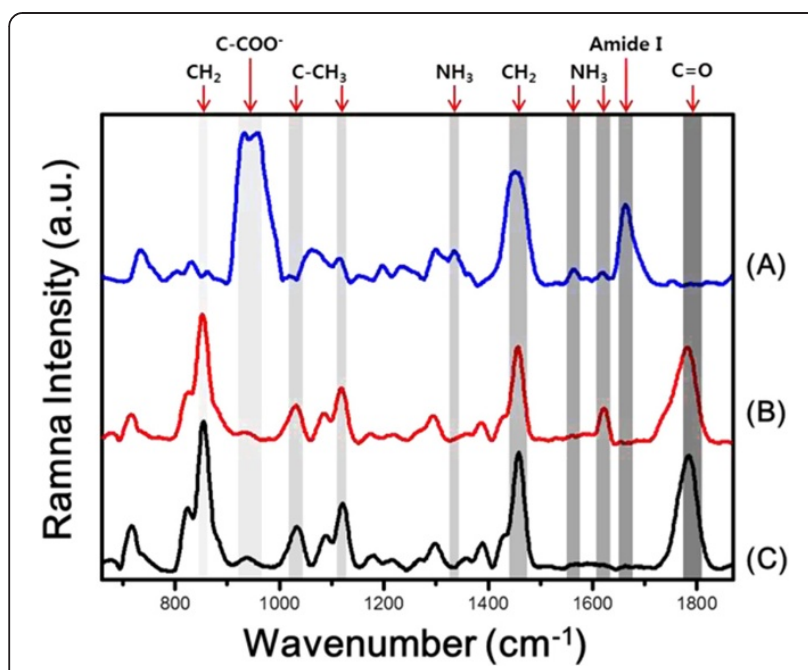

Figure 3 Compositional analysis of electrospun nanofibers by Raman spectroscopy. Raman spectra of RGD-M13 phages (A), RGD-M13 phage/PLGA nanofibers (B) and pure PLGA nanofibers (C).

Fibroblast behaviors on RGD-M13 phage/PLGA nanofiber matrices

We examined cellular behaviors of fibroblasts on the RGD-M13 phage/PLGA nanofiber matrices. In this study, three types of fibroblast were used: murine fibroblast cell lines (L-929 cells), primary human dermal fibroblasts (HDFs), and human fibrosarcoma cell lines (HT-1080 cells). The cell viability was measured to assess a cell attachment when cells had been seed on the matrices for 6 hours. As shown in Figure 4, fibroblasts showed the highest adhesion where they were cultured on RGD-M13 phage/PLGA matrices regardless of cell types. As mentioned above, RGD peptides contained the matrices have contributed to the enhancement of cell adhesion. In contrast, cell adhesion on pure PLGA matrices was

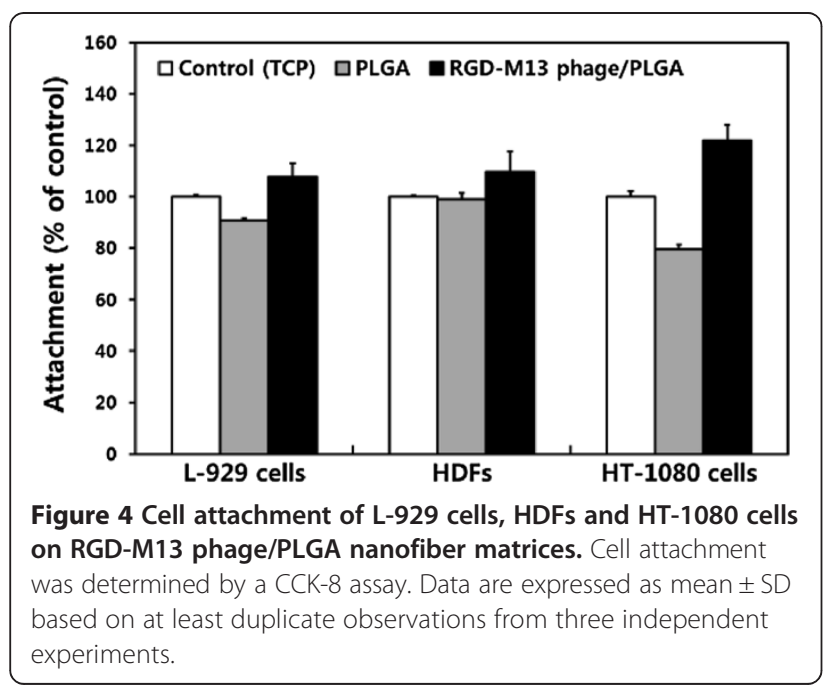

decreased because the PLGA matrices did not contain any materials which could improve cell adhesion. In addition, we evaluated the proliferation of fibroblasts on pure PLGA and RGD-M13 phage/PLGA matrices. As shown in Figure 5, the proliferation of fibroblasts was increased in a time-dependent manner. However, fibroblasts cultured on the RGD-M13 phage/PLGA matrices showed the highest proliferation as compared with that on pure PLGA matrices and even the control. These
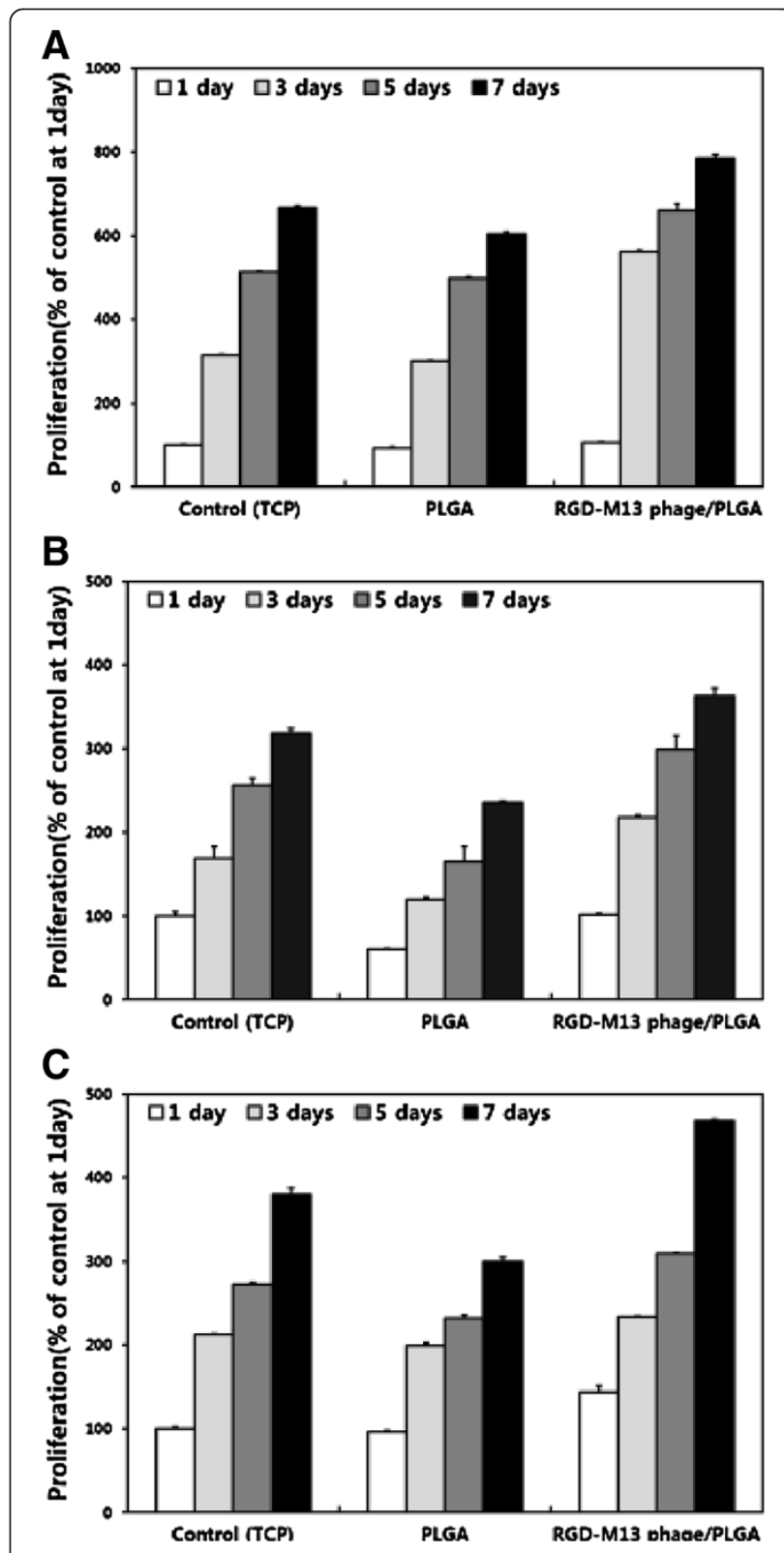

Figure 5 Cell proliferation of fibroblasts cultured on RGD-M13 phage/PLGA nanofiber matrices for $1-7$ days. Proliferation of L-929 cells (A), HDFs (B) and HT-1080 cells (C) were determined by a CCK-8 assay. Data are expressed as mean \pm SD based on at least duplicate observations from three independent experiments. 

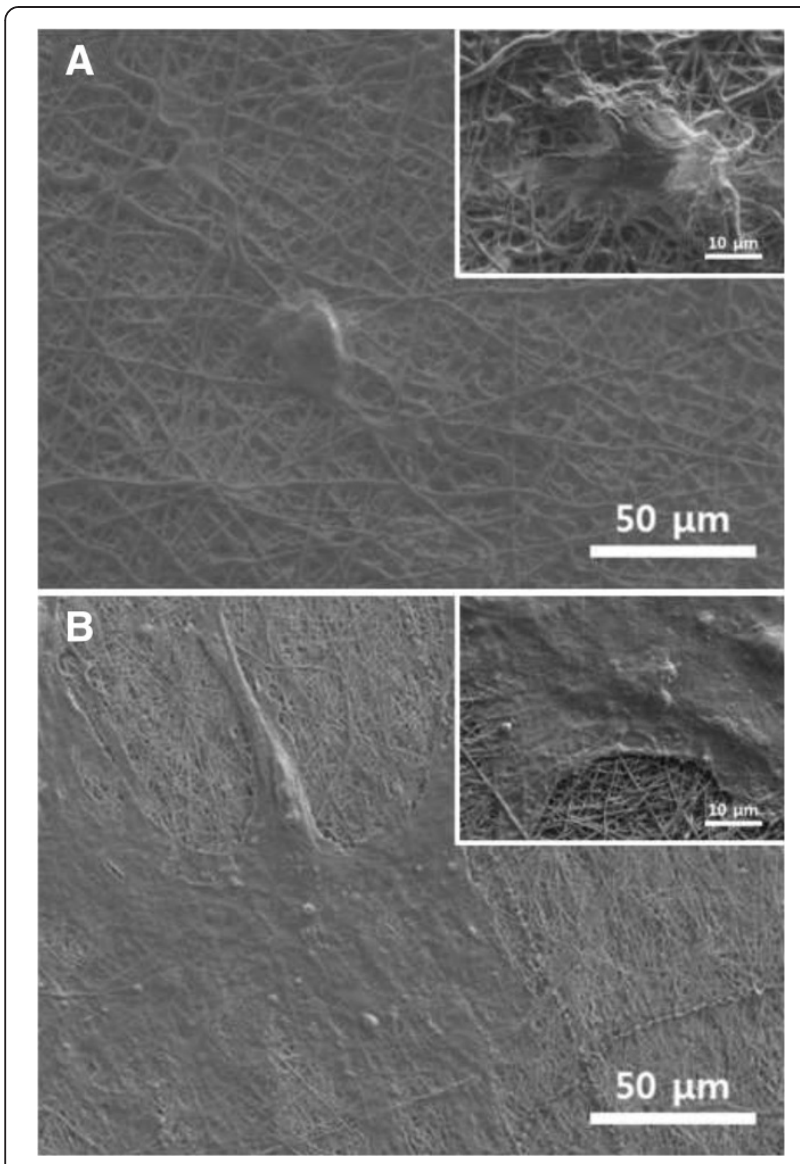

Figure 6 Cell morphology of HDFs grown on electrospun nanofiber matrices. SEM images of HDFs cultured on pure PLGA nanofiber matrices (A) and RGD-M13 phage/PLGA nanofiber matrices (B) for 3 days (magnification: in A and $C, \times 500$ and in B and $D, \times 2,000$ ). All photographs shown in this figure are representative of six independent experiments with similar results.

results implied that the RGD peptides effectively promote not only initial attachment but also proliferation of fibroblasts to the matrices. In addition, proliferation of both cell lines and primary cells was increased. These results correspond well with previous studies. It has been reported that RGD-functionalized substrates are able to promote cell attachment [34,35]. It is suggested that RGD peptides enhance cellular behaviors regardless of the cell types.

SEM images of HDFs cultured on the pure PLGA and RGD-M13 phage/PLGA matrices were presented on Figure 6. As shown in Figure 6A, HDFs cultured on pure PLGA matrix showed abnormal morphologies because the cells could not properly attach to the matrices. In contrast, HDFs cultured on hybrid matrices presented typical and well-spread morphology (Figure 6B). This result indicated that the cells were effectively attached and grown on the hybrid matrices. Previous reports documented that the RGD peptides containing scaffolds enhance cellular activities of various cell types including attachment, proliferation and differentiation [36-38]. Moreover, the hybrid matrices were good at support cellular growth without losing their nanofibrous structure even in the cell culture environment. Therefore, it is demonstrated that the hybrid matrices are biofunctional scaffolds which can improve cellular behaviors as well as induce cellular attachment.

\section{Conclusions}

This study was designed to fabricate RGD-M13 phage/ PLGA hybrid matrices that could applied for tissue engineering scaffolds. The suitable scaffold should be biocompatible and biodegradable. In addition, its structure should have a porous structure which is analogous to the natural ECM in order to support the growth of cells. We successfully fabricated the RGD-M13 phage/PLGA matrices by using electrospinning and analyzed various properties of them. Results showed that the hybrid matrices had outstanding biocompatibility and suitable physicochemical properties as well as structurally comparable to the natural ECM. Moreover, they were biofunctional scaffolds which could effectively improve cellular attachment and proliferation through RGD peptides existed along the nanofibers. Based on these results, RGD-M13 phage/PLGA hybrid matrices had a high probability to use for biodegradable scaffolds. In summary, it is suggested that the RGD-M13 phage/PLGA hybrid matrices can be employed to bioactive scaffolds for tissue engineering application.

\section{Availability of supporting data}

There was no available supporting data.

\section{Competing interests}

The authors declare that they have no competing interests.

\section{Authors' contributions}

YCS and JHL designed the experiments, carried out characterizations of nanofibers fabricated by electrospinning and drafted the manuscript. JL and MJK participated in the cell cultures and in vitro assays. JWO carried out the genetic engineering of M13 bacteriophages. TWK performed the statistical analysis and helped to interpret data. DWH conceived of the study, participated in its design and coordination, and helped to draft the manuscript. All authors read and approved the final manuscript.

\section{Acknowledgement}

This study was supported by Basic Science Research Program through the National Research Foundation of Korea (NRF) funded by the Ministry of Education, Science and Technology (2012R1A2A2A02010181).

\section{Author details}

${ }^{1}$ Department of Cogno-Mechatronics Engineering, Pusan National University, Busan 609-735, Korea. ${ }^{2}$ Department of Nanomaterials Engineering, College of Nanoscience \& Nanotechnology, Pusan National University, Busan 609-735, Korea. ${ }^{3}$ Department of Design, College of Arts, Pusan National University, Busan 609-735, Korea. 
Received: 3 July 2014 Accepted: 29 August 2014

Published: 3 October 2014

\section{References}

1. Ingber DE, Folkman J: Mechanochemical switching between growth and differentiation during fibroblast growth factor-stimulated angiogenesis in vitro: role of extracellular matrix. J Cell Biol 1989, 109:317-330.

2. Juliano RL, Haskill S: Signal transduction from the extracellular matrix. J Cell Biol 1993, 120:577-585.

3. Meredith JE, Fazeli B, Schwartz MA: The extracellular matrix as a cell survival factor. Mol Biol Cell 1993, 4:953-961.

4. Thery M, Racine V, Pepin A, Piel M, Chen Y, Sibarita JB, Bornens M: The extracellular matrix guides the orientation of the cell division axis. Nat Cell Biol 2005, 7:947-953.

5. Mo XM, Xu CY, Kotaki M, Ramakrishna S: Electrospun P(LLA-CL) nanofiber: a biomimetic extracellular matrix for smooth muscle cell and endothelial cell proliferation. Biomaterials 2004, 25:1883-1890.

6. Fujihara K, Kotaki M, Ramakrishna S: Guided bone regeneration membrane made of polycaprolactone/calcium carbonate composite nano-fibers. Biomaterials 2005, 26:4139-4147.

7. Zhang YZ, Su B, Venugopal J, Ramakrishna S, Lim CT: Biomimetic and bioactive nanofi brous scaffolds from electrospun composite nanofibers. Int J Nanomed 2007, 2:623-638.

8. Beletsi A, Leontiadis L, Klepetsanis P, Ithakissios DS, Avgoustakis K: Effect of preparative variables on the properties of poly(dl-lactide-co-glycolide)methoxypoly(ethyleneglycol) copolymers related to their application in controlled drug delivery. Int J Pharm 1999, 182:187-197.

9. Ravichandran R, Ng CC, Liao S, Pliszka D, Raghunath M, Ramakrishna S, Chan CK: Biomimetic surface modification of titanium surfaces for early cell capture by advanced electrospinning. Biomed Mater 2012, 7:015001.

10. Wei K, Li Y, Lei X, Yang H, Teramoto A, Yao J, Abe K, Ko FK: Emulsion electrospinning of a collagen-like protein/PLGA fibrous scaffold: Empirical modeling and preliminary release assessment of encapsulated protein. Macromol Biosci 2011, 11:1526-1536.

11. Chen DW, Hsu YH, Liao JY, Liu SJ, Chen JK, Ueng SW: Sustainable release of vancomycin, gentamicin and lidocaine from novel electrospun sandwich-structured PLGA/collagen nanofibrous membranes. Int J Pharm 2012, 430:335-341.

12. Pytela R, Pierschbacher MD, Ginsberg MH, Plow EF, Ruoslahti E: Platelet membrane glycoprotein Ilb/Illa: member of a family of Arg-Gly-Aspspecific adhesion receptors. Science 1986, 231:1559-1562.

13. Ruoslahti E, Pierschbacher MD: New perspectives in cell adhesion: RGD and integrins. Science 1987, 238:491-497.

14. Staatz WD, Fok KF, Zutter MM, Adams SP, Rodriguez BA, Santoro SA: Identification of a tetrapeptide recognition sequence for the $a_{2} \beta$ integrin in collagen. J Biol Chem 1991, 266:7363-7367.

15. Ho MH, Wang DM, Hsieh HJ, Liu HC, Hsien TY, Lai JY, Ho LT: Preparation and characterization of RGD-immobilized chitosan scaffolds. Biomaterials 2005, 26:3197-3206.

16. Zhang L, Hum M, Wang M, Li Y, Chen H, Chu C, Jiang H: Evaluation of modifying collagen matrix with RGD peptide through periodate oxidation. J Biomed Mater Res A 2005, 73A:468-475.

17. Lee J, Cuddihy MJ, Kotov NA: Three-dimensional cell culture matrices: state of the art. Tissue Eng Part B 2008, 14:61-86.

18. Smith GP, Petrenko VA: Phage display. Chem Rev 1997, 97:391-410.

19. Dogic Z, Fraden S: Smectic phase in a colloidal suspension of semiflexible virus particles. Phys Rev Lett 1997, 78:2417-2420

20. Frenkel D, Solomon B: Filamentous phage as vector-mediated antibody delivery to the brain. Proc Natl Acad Sci U S A 2002, 99:5675-5679.

21. Yoo SY, Kobayashi M, Lee PP, Lee SW: Early osteogenic differentiation of mouse preosteoblasts induced by collagen-derived DGEA-peptide on nanofibrous phage tissue matrices. Biomacromolecules 2011, 12:987-996.

22. Zhu H, Cao B, Zhen Z, Laxmi AA, Li D, Liu S, Mao C: Controlled growth and differentiation of MSCs on grooved films assembled from monodisperse biological nanofibers with genetically tunable surface chemistries. Biomaterials 2011, 32:4744-4752.

23. Chung WJ, Oh JW, Kwak K, Lee BY, Meyer J, Wang E, Hexemer A, Lee SW: Biomimetic self-templating supramolecular structures. Nature 2011, 478:364-368.
24. Wang J, Wang L, Li X, Mao C: Virus activated artificial ECM induces the osteoblastic differentiation of mesenchymal stem cells without osteogenic supplements. Sci Rep 2013, 3:1242.

25. Merzlyak A, Indrakanti S, Lee SW: Genetically engineered nanofiber-like viruses for tissue regenerating materials. Nano Lett 2009, 9:846-852.

26. Lee SW, Belcher AM: Virus-based fabrication of micro- and nanofibers using electrospinning. Nano Lett 2004, 4:387-390.

27. Chen G, Courey AJ: Generation of epitope-tagged proteins by inverse PCR mutagenesis. Biotechniques 1999, 26:814-816.

28. Qi D, Scholthof KB: A one-step PCR-based method for rapid and efficient site-directed fragment deletion, insertion, and substitution mutagenesis. J Virol Methods 2008, 149:85-90.

29. Lee EJ, Lee JH, Shin YC, Hwang DG, Kim JS, Jin OS, Jin L, Hong SW, Han DW Graphene oxide-decorated PLGA/collagen hybrid fiber sheets for application to tissue engineering scaffolds. Biomater Res 2014, 18:18-24.

30. Atabaev TS, Jin OS, Lee JH, Han DW, Vu HHT, Hwang YH, Kim HK: Facile synthesis of bifunctional silica-coated core-shell Y2O3:Eu3+, $\mathrm{Co}+$ composite particles for biomedical applications. RSC Adv 2012, 2:9495-9501.

31. Stewart S, Fredericks PM: Surface-enhanced Raman spectroscopy of amino acids adsorbed on an electrochemically prepared silver surface. Spectrochim Acta A 1999, 55:1641-1660.

32. Apeldoorn AA, Manen HJ, Bezemer JM, Bruijn JD, Blitterswijk CA, Otto C: Raman imaging of PLGA microsphere degradation inside macrophages. J Am Chem Soc 2004, 126:13226-13227.

33. Filho PF, Freire PTC, Lima KCV, Filho JM, Melo FEA, Pizani PS: High temperature raman spectra of L-leucine crystals. Braz J Phys 2008, 38:131-137.

34. Hersel U, Dahmen C, Kessler H: RGD modified polymers: biomaterials for stimulated cell adhesion and beyond. Biomaterials 2003, 24:4385-4415.

35. Bellis SL: Advantages of RGD peptides for directing cell association with biomaterials. Biomaterials 2011, 32:4205-4210.

36. Tsai WB, Chen YR, Liu HL: RGD-conjugated crosslinked chitosan scaffolds for culture and osteogenic differentiation of mesenchymal stem cells. J Taiwan Inst Chem E 2013, 44:17.

37. Shin YM, Jo SY, Park JS, Gwon HJ, Jeong SI, Lim YM: Synergistic effect of dual-functionalized fibrous scaffold with BCP and RGD containing peptide for improved osteogenic differentiation. Macromol Biosci 2014 doi:10.1002/mabi.201400023.

38. Masaeli E, Wieringa PA, Morshed M, Nasr-Esfahani MH, Sadri S, Blitterswijk CA, Moroni L: Peptide functionalized polyhydroxyalkanoate nanofibrous scaffolds enhance Schwann cells activity. Nanomedicine 2014. doi:10.1016/ j.nano.2014.04.008

doi:10.1186/2055-7124-18-14

Cite this article as: Shin et al:: Cell-adhesive RGD peptide-displaying M13 bacteriophage/PLGA nanofiber matrices for growth of fibroblasts. Biomaterials Research 2014 18:14.

\section{Submit your next manuscript to BioMed Central and take full advantage of:}

- Convenient online submission

- Thorough peer review

- No space constraints or color figure charges

- Immediate publication on acceptance

- Inclusion in PubMed, CAS, Scopus and Google Scholar

- Research which is freely available for redistribution 